\title{
Sodium-glucose cotransporter inhibitors may reduce the risk of pneumonia: an updated meta-analysis of cardiovascular outcome trials
}

\author{
Fotios Barkas ${ }^{1}\left[\right.$. Georgia Anastasiou ${ }^{1} \cdot$ Haralampos Milionis $^{1} \cdot$ Evangelos Liberopoulos $^{1}$
}

Received: 22 April 2021 / Accepted: 25 May 2021 / Published online: 6 June 2021

(c) The Japan Diabetes Society 2021

\begin{abstract}
The present meta-analysis included 8 cardiovascular outcome trials with 57,185 patients at high cardiometabolic risk. In comparison with placebo, treatment with sodium-glucose cotransporter inhibitors was associated with a significantly lower risk of pneumonia (RR $0.85,95 \%$ CI $0.76-0.95, p=0.004 ; I^{2}=0, p=0.48$ ).
\end{abstract}

Keywords Cardiovascular · Sodium-glucose cotransporter inhibitor · Canagliflozin · Dapagliflozin · Empagliflozin · Ertugliflozin $\cdot$ Sotagliflozin

\section{Introduction}

Sodium-glucose cotransporter inhibitors (SGLTi) have been associated with impressive cardio-nephro-metabolic benefits in patients with and without diabetes [1]. Although they have been linked with increased incidence of lower genital tract infections, a meta-analysis has recently demonstrated a possible protective effect against incident pneumonia [2]. The latter might be of great interest during the current pandemic of coronavirus disease 2019 (COVID-19). In this context, we performed an updated meta-analysis of cardiovascular outcome trials (CVOTs) investigating the association of SGLTi with the risk of incident pneumonia.

\section{Methods}

The present meta-analysis was based on PRISMA guidelines. Double-blind placebo controlled randomized trials (RCTs) were included in the present meta-analysis if they: (a) represented CVOTs, (b) compared any SGLTi

Evangelos Liberopoulos

vaglimp@yahoo.com; elibero@uoi.gr

1 Department of Internal Medicine, Faculty of Medicine, School of Health Sciences, University of Ioannina, 45 110, Ioannina, Greece with placebo and (c) included pneumonia in their reported adverse events. Adverse events reported as 'pneumonia' were the outcome of interest. Relevant trials were identified by searching MEDLINE, EMBASE and CENTRAL databases up to 07 Mar 2021 using the following terms: 'cardiovascular', 'sodium-glucose cotransporter inhibitor', 'canagliflozin', 'dapagliflozin', 'empagliflozin', 'ertugliflozin' and 'sotagliflozin'. Two review authors (FB and GA) independently extracted data using a pre-designed data extraction form that contained publication details, study population, randomization, allocation concealment, details of blinding measures, description of interventions and results. Any differences between them were resolved by consulting the other review authors (HM, EL). Bias risk assessment was based on the revised Cochrane riskof-bias tool for randomized trials (RoB 2). We estimated treatment effect using risk ratio (RR) and 95\% confidence intervals (CI). Analyses were performed with Revman 5.1. RCTs not reporting the outcome of interest have not been included in this analysis. Heterogeneity between trial results was tested using a standard chi-squared test; $p<0.1$ was considered statistically significant. $I^{2}$ statistic was used as a measure of heterogeneity. In case of significant heterogeneity $\left(I^{2} \geq 50 \%\right)$, a random-effects model was used. 
Table 1 Characteristics of the trials included in the meta-analysis

\begin{tabular}{|c|c|c|c|c|c|c|c|}
\hline & \multicolumn{2}{|l|}{ EMPA-REG } & CANVAS & DECLARE-TIMI 58 & \multicolumn{2}{|c|}{ CREDENCE } & VERTIS-CV \\
\hline $\begin{array}{l}\text { National clinical trial } \\
\text { number }\end{array}$ & \multicolumn{2}{|c|}{ NCT01131676 } & $\begin{array}{l}\text { NCT01032629 } \\
\text { NCT01989754 }\end{array}$ & NCT01730534 & \multicolumn{2}{|c|}{ NCT02065791 } & NCT01986881 \\
\hline Drug & \multicolumn{2}{|c|}{ Empagliflozin } & Canagliflozin & Dapagliflozin & \multicolumn{2}{|c|}{ Canagliflozin } & Ertugliflozin \\
\hline Comparator & \multicolumn{2}{|l|}{ Placebo } & Placebo & Placebo & \multicolumn{2}{|l|}{ Placebo } & Placebo \\
\hline Study participants & \multicolumn{2}{|l|}{7020} & 10,142 & 17,160 & \multicolumn{2}{|l|}{4401} & 8246 \\
\hline Duration, years & \multicolumn{2}{|l|}{3.1} & 3.6 & 4.2 & \multicolumn{2}{|l|}{2.62} & 3.5 \\
\hline Outcome of interest & \multirow{2}{*}{\multicolumn{2}{|c|}{$\begin{array}{l}\text { Primary endpoint: } \\
\text { cardiovascular } \\
\text { death, myocardial } \\
\text { infarction, stroke }\end{array}$}} & $\begin{array}{l}\text { Primary endpoint: } \\
\text { cardiovascular } \\
\text { death, myocardial } \\
\text { infarction, stroke }\end{array}$ & $\begin{array}{l}\text { Primary endpoint: } \\
\text { cardiovascular } \\
\text { death, myocardial } \\
\text { infarction, stroke }\end{array}$ & \multirow{2}{*}{\multicolumn{2}{|c|}{$\begin{array}{l}\text { Secondary endpoint: } \\
\text { cardiovascular } \\
\text { death, myocardial } \\
\text { infarction, or stroke }\end{array}$}} & $\begin{array}{l}\text { Primary endpoint: } \\
\text { cardiovascular } \\
\text { death, myocardial } \\
\text { infarction, or stroke }\end{array}$ \\
\hline $\begin{array}{l}\text { Patients' character- } \\
\text { istics }\end{array}$ & & & & & & & \\
\hline Age, years & \multicolumn{2}{|l|}{$63.2 \pm 8.8$} & $63.2 \pm 8.3$ & $63.9 \pm 6.8$ & \multicolumn{2}{|l|}{$63 \pm 9.2$} & $64.4 \pm 8.1$ \\
\hline Gender (male), $\%$ & \multicolumn{2}{|l|}{72.0} & 64.9 & 62.6 & \multicolumn{2}{|l|}{66.1} & 69.9 \\
\hline $\begin{array}{l}\text { Diabetes duration, } \\
\text { years }\end{array}$ & \multicolumn{2}{|l|}{ N/A } & $13.5 \pm 7.7$ & $11(6-16)$ & \multicolumn{2}{|l|}{$15.8 \pm 8.6$} & $13 \pm 8.3$ \\
\hline $\begin{array}{c}\text { Baseline glycated } \\
\text { hemoglobin, } \%\end{array}$ & \multicolumn{2}{|l|}{$8.1 \pm 0.8$} & $8.2 \pm 0.9$ & $8.3 \pm 1.2$ & \multicolumn{2}{|l|}{$8.3 \pm 1.3$} & $8.2 \pm 1.1$ \\
\hline $\begin{array}{l}\text { Baseline body mass } \\
\text { index, } \mathrm{kg} / \mathrm{m}^{2}\end{array}$ & \multicolumn{2}{|l|}{$30.7 \pm 5.2$} & $31.9 \pm 5.9$ & $32.1 \pm 6.0$ & \multicolumn{2}{|l|}{$31.3 \pm 6.2$} & $31.9 \pm 5.4$ \\
\hline $\begin{array}{l}\text { Systolic blood pres- } \\
\text { sure, } \mathrm{mmHg}\end{array}$ & \multicolumn{2}{|l|}{$136 \pm 17$} & $136 \pm 16$ & $135 \pm 15$ & \multicolumn{2}{|l|}{$140 \pm 15.6$} & $113 \pm 14$ \\
\hline $\begin{array}{l}\text { Diastolic blood pres- } \\
\text { sure, } \mathrm{mmHg}\end{array}$ & \multicolumn{2}{|l|}{$77 \pm 10$} & $78 \pm 10$ & $85 \pm 16$ & \multicolumn{2}{|l|}{$78 \pm 9$} & $77 \pm 8$ \\
\hline $\begin{array}{l}\text { History of cardiovas- } \\
\text { cular disease, } \%\end{array}$ & 99.0 & & 72.2 & 40.6 & 50.4 & & 100.0 \\
\hline Heart failure, $\%$ & 10.5 & & 14.4 & 10.0 & 29.4 & & 23.7 \\
\hline $\begin{array}{l}\text { Estimated glo- } \\
\text { merular filtration } \\
\text { rate }<60 \mathrm{ml} / \\
\min / 1.73 \mathrm{~m}^{2}, \%\end{array}$ & 25.9 & & 20.1 & 7.4 & 59.8 & & 21.9 \\
\hline Diabetes, $\%$ & 100 & & 100 & 100 & 100 & & 100 \\
\hline & & SOLOIS & & DAPA-HF & & DAPA-Cl & \\
\hline National clinical trial nu & umber & NCT03. & 934 & NCT03036124 & & NCT0303 & 6150 \\
\hline Drug & & Sotaglif & & Dapagliflozin & & Dapaglifl & zin \\
\hline Comparator & & Placebo & & Placebo & & Placebo & \\
\hline Study participants & & 1222 & & 4744 & & 4304 & \\
\hline Duration, years & & 0.8 & & 1.5 & & 2.4 & \\
\hline Outcome of interest & & $\begin{array}{l}\text { Primary } \\
\text { death, } \\
\text { failure }\end{array}$ & $\begin{array}{l}\text { dpoint: cardiovascular } \\
\text { spitalization for heart } \\
\text { rgent heart failure visits }\end{array}$ & $\begin{array}{r}\text { Primary endpoint: ca } \\
\text { death, hospitalizatic } \\
\text { failure, urgent heart }\end{array}$ & $\begin{array}{l}\text { liovascular } \\
\text { for heart } \\
\text { ailure visits }\end{array}$ & $\begin{array}{c}\text { Primary e } \\
\text { at least } \\
\text { GFR, or } \\
\text { disease }\end{array}$ & $\begin{array}{l}\text { Adpoint: a decline of } \\
0 \% \text { in the estimated } \\
\text { set of end-stage kidney }\end{array}$ \\
\hline Patients' characteristics & & & & & & & \\
\hline Age, years & & $70(63-$ & & $66.2 \pm 10.9$ & & $61.9 \pm 12$ & \\
\hline Gender (male), $\%$ & & 66.2 & & 76.6 & & 66.9 & \\
\hline Diabetes duration, yea & & N/A & & N/A & & N/A & \\
\hline Baseline glycated hem & noglobin, \% & $7.2(6.4$ & & N/A & & N/A & \\
\hline Baseline body mass in & adex, $\mathrm{kg} / \mathrm{m}^{2}$ & $31.1(26$ & $-34.5)$ & $28.2 \pm 6.0$ & & $29.5 \pm 6.2$ & \\
\hline Systolic blood pressure & $\mathrm{re}, \mathrm{mmHg}$ & $122(11$ & 135) & $122 \pm 16$ & & $137 \pm 17$ & \\
\hline Diastolic blood pressu & ure, $\mathrm{mmHg}$ & $73(66-$ & & N/A & & $78 \pm 11$ & \\
\hline $\begin{array}{l}\text { History of cardiovascu } \\
\%\end{array}$ & ular disease, & N/A & & N/A & & 37.4 & \\
\hline
\end{tabular}


Table 1 (continued)

\begin{tabular}{llll}
\hline & SOLOIST & DAPA-HF & DAPA-CKD \\
\hline Heart failure, $\%$ & 100.0 & 100.0 & 10.9 \\
\hline $\begin{array}{c}\text { Estimated glomerular filtration } \\
\text { rate }<60 \mathrm{ml} / \mathrm{min} / 1.73 \mathrm{~m}^{2}, \%\end{array}$ & 69.8 & 40.6 & 90.0 \\
\begin{tabular}{l} 
Diabetes, $\%$ \\
\hline
\end{tabular} & 100.0 & 45.0 & 67.5 \\
\hline
\end{tabular}

Variables are expressed as mean \pm standard deviation or median (interquartile range), unless percentages are shown

EMPA-REG (Empagliflozin) Cardiovascular Outcome Event Trial in Type 2 Diabetes Mellitus Patients, CANVAS Canagliflozin Cardiovascular Assessment Study, CREDENCE Canagliflozin and Renal Events in Diabetes with Established Nephropathy Clinical Evaluation, DECLARETIMI 58, Multicenter Trial to Evaluate the Effect of Dapagliflozin on the Incidence of Cardiovascular Events, N/A not applicable, VERTIS-CV Evaluation of Ertugliflozin Efficacy and Safety Cardiovascular Outcomes Trial, SOLOIST-WHF Effect of Sotagliflozin on Cardiovascular Events in Patients with Type 2 Diabetes Post Worsening Heart Failure, DAPA-HF Study to Evaluate the Effect of Dapagliflozin on the Incidence of Worsening Heart Failure or Cardiovascular Death in Patients with Chronic Heart Failure, DAPA-CKD A Study to Evaluate the Effect of Dapagliflozin on Renal Outcomes and Cardiovascular Mortality in Patients With Chronic Kidney Disease, N/A not applicable

\section{Results}

Our literature search identified eight eligible CVOTs (EMPAREG OUTCOME, DECLARE-TIMI 58, CANVAS, CREDENCE, VERTIS-CV, SOLOIST, DAPA-CKD, DAPA-HF; Supplementary Fig. 1) [3-10]. A total of 57,185 subjects (1222-17,160 in each trial) followed-up for 0.8-4.2 years were included. Of those, $93 \%$ were diagnosed with type 2 diabetes, $65 \%$ with atherosclerotic cardiovascular disease, $23 \%$ with heart failure and 32\% with chronic kidney disease (Table 1). A total of 1316 cases of pneumonia were recorded during follow-up.

The pooled analysis showed that SGLTi were associated with a significantly reduced risk of pneumonia in comparison with placebo (RR 0.85, 95\% CI 0.76-0.95, $p=0.004 ; I^{2}=0, p=0.48$ ) (Fig. 1). Low bias risk was noted within the included studies (Supplementary Fig. 2).

\section{Discussion}

The present meta-analysis shows that treatment with SGLTi is associated with a lower incidence of pneumonia in patients at high cardiometabolic risk compared with placebo.

A recent meta-analysis of 6 CVOTs with 47,728 participants assigned to treatment with either SGLT2i or placebo demonstrated that there was no difference in the risk of upper respiratory tract infection (RR $0.95,95 \%$ CI $0.48-1.88, I^{2}=0 \%$ ), lower respiratory tract infection (RR $0.66,95 \%$ CI $0.39-1.13$, $I^{2}=0 \%$ ), viral infection (RR $1.15,95 \%$ CI $\left.0.49-2.71, I^{2}=0 \%\right)$ and influenza (RR 1.27, 95\% CI 0.70-2.32, $I^{2}=0 \%$ ) [2]. However, the pooled analysis of 5 RCTs $(n=43,430)$ showed that SGLT2i were associated with decreased risk of pneumonia (RR $0.85,95 \%$ CI $0.75-0.97, I^{2}=0 \%$ ) [2]. After incorporating the results of VERTIS-CV, DAPA-CKD and SOLOIST, our metaanalysis is the largest $(n=57,185)$ and most updated to include all available CVOTs reporting on the risk of pneumonia as an adverse event.

Possible pathophysiological explanations that might account for the observed reduction in the risk of pneumonia include activation of M2 macrophages, inhibition of lipid raft formation, increased production of ketone bodies, prevention of cytosolic $\mathrm{pH}$ reduction and induced shift of energy metabolism towards an increased reliance on lipid oxidation [11-13]. The reasons for the differential association of SGLT2 $i$ with the risk of pneumonia versus upper or lower respiratory infection are unknown [2]. Considering the inflammatory pathways involved in the pathophysiology of pneumonia, the anti-inflammatory properties of SGLT2i may be more relevant [14]. Furthermore, pneumonia is a more objective endpoint since its diagnosis is established with imaging criteria.

Although almost all included studies were completed before the onset of the current pandemic, SGLTi treatment merits a role in the COVID-19 era [15]. A propensity-score-matched cohort study $(n=24,865)$ showed no increased risk of COVID19 amongst patients treated with SGLT2i compared with dipeptidyl-peptidase 4 inhibitors (adjusted hazard ratio: 0.92, 95\% CI 0.66-1.29) [16]. Furthermore, background SGLTi treatment in hospitalized diabetic patients with COVID-19 $(n=2666)$ has been associated with lower risk of in-hospital mortality (19.4 vs $39.1 \%, p=0.003$ ) as compared with other glucose-lowering drugs [17]. A similar beneficial effect of SGLT2i on the mortality risk in patients with diabetes and COVID-19 (hazard ratio: $0.82,95 \%$ CI $0.74-0.91$ ) has been confirmed by a larger observational cohort $(n=2,851,465)$. [18].

The fact that pneumonia was not the primary outcome of the included studies and was not adjudicated should be acknowledged as a limitation of the present meta-analysis. On the other hand, this is the largest and most updated one to evaluate the association of SGLTi treatment with the risk of pneumonia. 


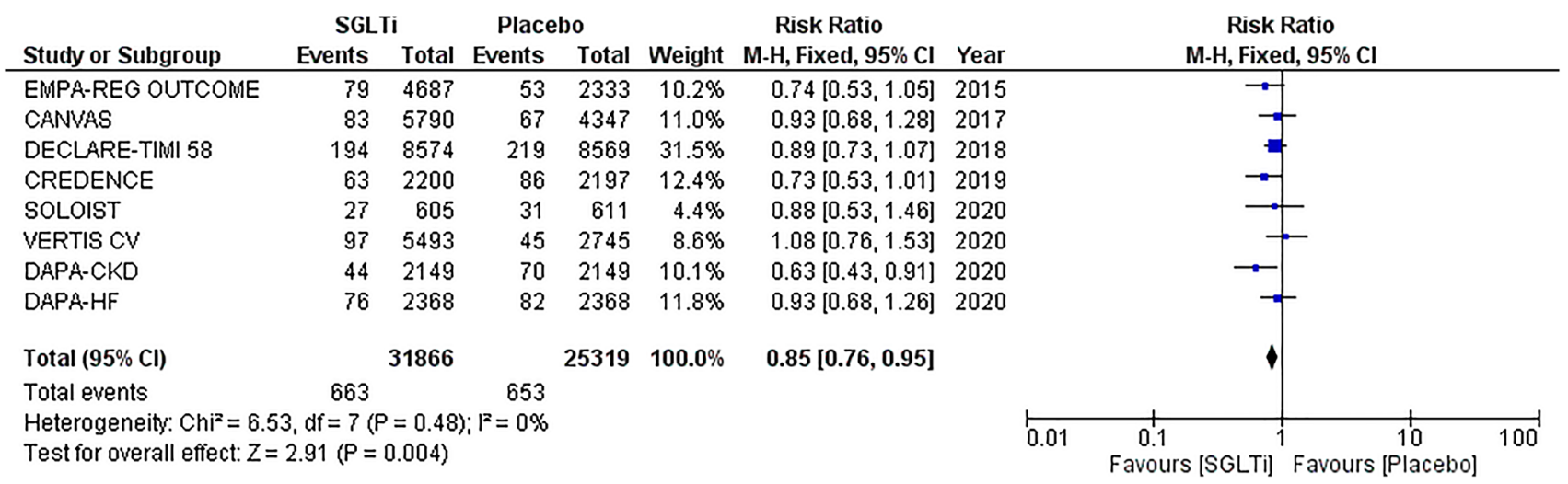

Fig. 1 Forest plot of pneumonia risk. SGLTi sodium-glucose cotransporter inhibitors, CI confidence interval

\section{Conclusions}

The present meta-analysis confirms that treatment with SGLTi is associated with a lower risk of pneumonia compared with placebo in patients at high cardiometabolic risk. In this context, ongoing RCTs (DARE-19 and TACTICE) will elucidate the efficacy and safety of SGLTi on the progression, complications and mortality associated with COVID-19 [11, 19]. Considering their cardiovascular benefit, SGLTi should not be interrupted during current pandemic. Nevertheless, they should be cautiously used in case of severe disease.[20].

Supplementary Information The online version contains supplementary material available at https://doi.org/10.1007/s13340-021-00515-4.

Author contributions FB and GA contributed to the acquisition, analysis and interpretation of data and drafted the present work. EL and HM contributed to the conception or design of the present work and critically revised the manuscript. All authors approved the version to be published and agreed to be accountable for all aspects of the work in ensuring that questions related to the accuracy or integrity of any part of it are appropriately investigated and resolved.

Funding The authors received no financial support for the research, authorship, and/or publication of this article.

\section{Declarations}

Conflict of interest The authors declare that they have no conflict of interest.

Research involving human participants The present work is a metaanalysis including already published results from RCTs.[3-10]

\section{References}

1. Lopaschuk GD, Verma S. Mechanisms of cardiovascular benefits of sodium glucose co-transporter 2 (SGLT2) inhibitors: a state-of-the-art review. JACC Basic Transl Sci. 2020;5(6):632-44. https://doi.org/10. 1016/j.jacbts.2020.02.004.

2. Patoulias D, Papadopoulos C, Boulmpou A, Doumas M. Metaanalysis of the hallmark cardiovascular and renal outcome trials addressing the risk for respiratory tract infections with sodiumglucose co-transporter-2 inhibitors; implications for COVID19 pandemic. Diabetes Obes Metab. 2021. https://doi.org/10.1111/ dom.14359.

3. Bhatt DL, Szarek M, Steg PG, Cannon CP, Leiter LA, McGuire DK, et al. Sotagliflozin in patients with diabetes and recent worsening heart failure. N Engl J Med. 2021;384(2):117-28. https://doi.org/10.1056/NEJMoa2030183.

4. Heerspink HJL, Stefansson BV, Correa-Rotter R, Chertow GM, Greene T, Hou FF, et al. Dapagliflozin in patients with chronic kidney disease. N Engl J Med. 2020;383(15):1436-46. https:// doi.org/10.1056/NEJMoa2024816.

5. McMurray JJV, Solomon SD, Inzucchi SE, Kober L, Kosiborod MN, Martinez FA, et al. Dapagliflozin in patients with heart failure and reduced ejection fraction. N Engl J Med. 2019;381(21):1995-2008. https://doi.org/10.1056/NEJMoa1911 303.

6. Neal B, Perkovic V, Mahaffey KW, de Zeeuw D, Fulcher G, Erondu N, et al. Canagliflozin and cardiovascular and renal events in type 2 diabetes. N Engl J Med. 2017;377(7):644-57. https://doi.org/10.1056/NEJMoa1611925.

7. Packer M, Anker SD, Butler J, Filippatos G, Pocock SJ, Carson $\mathrm{P}$, et al. Cardiovascular and renal outcomes with empagliflozin in heart failure. N Engl J Med. 2020;383(15):1413-24. https:// doi.org/10.1056/NEJMoa2022190.

8. Perkovic V, Jardine MJ, Neal B, Bompoint S, Heerspink HJL, Charytan DM, et al. Canagliflozin and renal outcomes in type 2 diabetes and nephropathy. N Engl J Med. 2019;380(24):2295306. https://doi.org/10.1056/NEJMoa1811744.

9. Wiviott SD, Raz I, Bonaca MP, Mosenzon O, Kato ET, Cahn A, et al. Dapagliflozin and cardiovascular outcomes in type 2 diabetes. N Engl J Med. 2019;380(4):347-57. https://doi.org/ 10.1056/NEJMoa1812389.

10. Zinman B, Wanner C, Lachin JM, Fitchett D, Bluhmki E, Hantel $\mathrm{S}$, et al. Empagliflozin, cardiovascular outcomes, and mortality in type 2 diabetes. N Engl J Med. 2015;373(22):2117-28. https://doi.org/10.1056/NEJMoa1504720.

11. Kosiborod M, Berwanger O, Koch GG, Martinez F, Mukhtar O, Verma S, et al. Effects of dapagliflozin on prevention of major clinical events and recovery in patients with respiratory failure because of COVID-19: design and rationale for the DARE-19 study. Diabetes Obes Metab. 2020. https://doi.org/10.1111/dom. 14296. 
12. Scheen AJ. SGLT2 inhibition during the COVID-19 epidemic: friend or foe? Diabetes Metab. 2020;46(5):343-4. https://doi. org/10.1016/j.diabet.2020.06.003.

13. Lee YJ, Kim MO, Ryu JM, Han HJ. Regulation of SGLT expression and localization through Epac/PKA-dependent caveolin-1 and $\mathrm{F}$-actin activation in renal proximal tubule cells. Biochim Biophys Acta. 2012;1823(4):971-82. https://doi.org/10.1016/j. bbamcr.2011.12.011.

14. Barkas F, Milionis H, Anastasiou G, Liberopoulos E. Statins and PCSK9 inhibitors: what is their role in coronavirus disease 2019? Med Hypotheses. 2021. https://doi.org/10.1016/j.mehy. 2020.110452.

15. Anastasiou G, Hatziagelaki E, Liberopoulos E. Could dapagliflozin attenuate COVID-19 progression in high-risk patients with or without diabetes? Behind DARE-19 concept. J Cardiovasc Pharmacol. 2021. https://doi.org/10.1097/FJC.0000000000 001011.

16. Sainsbury C, Wang J, Gokhale K, Acosta-Mena D, Dhalla S, Byne N, et al. Sodium-glucose co-transporter-2 inhibitors and susceptibility to COVID-19: a population-based retrospective cohort study. Diabetes Obes Metab. 2021;23(1):263-9. https:// doi.org/10.1111/dom.14203.

17. Perez-Belmonte LM, Torres-Pena JD, Lopez-Carmona MD, Ayala-Gutierrez MM, Fuentes-Jimenez F, Huerta LJ, et al. Mortality and other adverse outcomes in patients with type 2 diabetes mellitus admitted for COVID-19 in association with glucose-lowering drugs: a nationwide cohort study. BMC Med. 2020;18(1):359. https://doi.org/10.1186/s12916-020-01832-2.
18. Khunti K, Knighton P, Zaccardi F, Bakhai C, Barron E, Holman N, et al. Prescription of glucose-lowering therapies and risk of COVID-19 mortality in people with type 2 diabetes: a nationwide observational study in England. Lancet Diabetes Endocrinol. 2021;9(5):293-303. https://doi.org/10.1016/S22138587(21)00050-4.

19. Lu IN, Kulkarni S, Fisk M, Kostapanos M, Banham-Hall E, Kadyan S, et al. muLTi-Arm Therapeutic study in pre-ICu patients admitted with Covid-19-Experimental drugs and mechanisms (TACTIC-E): a structured summary of a study protocol for a randomized controlled trial. Trials. 2020;21(1):690. https://doi.org/10.1186/s13063-020-04618-2.

20. Li J, Wang X, Chen J, Zuo X, Zhang H, Deng A. COVID-19 infection may cause ketosis and ketoacidosis. Diabetes Obes Metab. 2020;22(10):1935-41. https://doi.org/10.1111/dom. 14057.

Publisher's Note Springer Nature remains neutral with regard to jurisdictional claims in published maps and institutional affiliations. 